\title{
FLEXURAL PROPERTIES OF ALKALINE TREATED SUGAR PALM FIBRE REINFORCED EPOXY COMPOSITES
}

\section{Bachtiar, S.M. Sapuan and M.M. Hamdan}

\author{
Department of Mechanical \& Manufacturing Engineering, Faculty of Engineering, \\ Universiti Putra Malaysia, 43400 UPM Serdang, Selangor, Malaysia \\ Tel.: +603-89466437. Fax: +609-87654321 \\ E-mail: sapuan@eng.upm.edu.my
}

\begin{abstract}
A study of the effect of alkaline treatment on the flexural properties of sugar palm fibre reinforced epoxy composites is presented in this paper. The composites were reinforced with $10 \%$ weight fraction of the fibres. The fibres were treated using sodium hydroxide $(\mathrm{NaOH})$ with $0.25 \mathrm{M}$ and $0.5 \mathrm{M}$ concentration solution for 1 hour, 4 hours and 8 hours soaking time. The purpose of treating fibres with alkali was to enhance the interfacial bonding between matrix and fibre surfaces. The maximum flexural strength occurred at $0.25 \mathrm{M} \mathrm{NaOH}$ solution with 1 hour of soaking time, i.e $96.71 \mathrm{MPa}$, improving by $24.41 \%$ from untreated fibre composite. But, the maximum flexural modulus took place at $0.5 \mathrm{M} \mathrm{NaOH}$ solution with 4 hours soaking time, i.e. $6948 \mathrm{MPa}$, improving by $148 \%$ from untreated composite.
\end{abstract}

Key words: Arenga pinnata, flexural property, interfacial bonding, alkaline treatment.

\section{INTRODUCTION}

Natural fibre composites find their application in many industries like building construction, furniture, automotive and packaging due to some advantages that they offer: they are non-abrasive to machines, renewable, bio-degradable and an abundant source of fibre, are of low cost, and have acceptable mechanical properties. Natural fibres such as hemp, flax, abaca, sisal, jute, henequen (Herrera-Franco et al., 2004), kenaf, ramie, sugar palm, oil palm, pineapple leaf, banana pseudo-stem, sugarcane bagasse, coir, rice husk, wood, bamboo, chicken feather (Wool, 2005), silk and cotton have been reported as being used as fibres in polymer composites. However, these promising fibres possess some negative characteristics: they are highly hydrophilic and they can vary a lot in properties because of the influence of their growing conditions, fibre processing technique, the fineness of the fibre and sample test-length, which makes accurate predictions of the respective composite properties difficult. Moreover, natural fibres have a complex structure of elementary fibres, consisting of cellulose, hemicelluloses, pectin, lignin, and others, and thus they are not to be considered in the same, straightforward way as monofilament fibres (Saheb and Jog, 1999). The main issue in the use of natural fibre composites is the fibre matrix adhesion. The function of the matrix is to transfer the load to the stiff fibres through shear stresses at the interface. This can be achieved if a sufficient bonding between the matrix and the fibres is ensured. Insufficient interfacial bonding at the interface implies that their advantages cannot be fully utilized and that they are exposed to environmental attacks. Poor adhesion between hydrophobic polymers and hydrophilic fibres implies poor properties 
for the composites. These properties can be improved by physical treatments (cold plasma treatment and corona treatment) and chemical treatments (maleic anhydride, organosilanes, isocyanates, sodium hydroxide, permanganate and peroxide) (Wambua et al., 2003). Rowell (1998) gave considerations for the selection of a fibre chemical treatment such as ability to react with hydroxyl groups, its toxicity, easy to removal after treatment, low boiling point liquid, effective at low temperature, and cost. Alkali treatment is also an alternative as many times these chemicals swell the cell wall matrix structure and give better penetration (Rowell, 1998).

Sugar palm fibre is a potential source of natural fibre from Arenga pinnata, a member of Palmae family. This plant commonly grows in tropical regions such as the Philippines, Malaysia and Indonesia. It is naturally a forest species. The full length of the trunk of an Arenga pinnata tree is completely covered by black fibre. This black fibre can be used for brooms, paint brushes, septic tank base filters, clear water filters, door mats, carpets, ropes, chair/sofa cushions, and for fish nests to hatch eggs (Suwartapraja, 2003). In certain regions, traditional application of ijuk includes handcraft for kupiah (Acehnese typical headgear used in prayer) and roofing for traditional houses in Mandailing, North Sumatera. The significance of the study is to try exploring the potential of the abundant natural resources from forests for use as a reinforcing fibre in composites. The use of sugar palm fibre also has an economical advantage if glass or carbon fibre can be replaced by this sugar palm fibre. Mechanical properties such as tensile properties, flexural properties, and morphological aspects of sugar palm fibre reinforced epoxy composites have been studied by Siregar (2005). The study of the mechanical properties of sugar palm fibre reinforced epoxy composites gave promising results. The results of flexural strength tests of sugar palm fibre reinforced epoxy composites indicated that the $10 \mathrm{wt} \%$ woven roving fibre has the highest value compared to other fibre contents and arrangements. The work of Siregar (2005) has shown that using sugar palm fibres as a reinforcement agent for the epoxy matrix has provided a new form of composite with good strength and rigidity.

Suriani et al. (2007) examined or studied the interfacial adhesion of tensile specimens of sugar palm fibre reinforced epoxy composites. The composite specimens were prepared at various fibre weights of $10 \%, 15 \%$ and $20 \%$ with different fibre orientations such as woven roving, long random and chopped random. Interfacial adhesion study of tensile strength specimens reveals that the woven roving fibre composites gave good interface adhesion between the fibre and the matrix as compared to long random and chopped random fibre reinforced epoxy composites. However, none of the earlier studies looked into the effect of alkaline treatment of fibre on flexural properties of the composites and therefore, such a study is presented in this paper.

\section{MATERIALS AND METHODS}

The procedures of the present study include preparation of materials, i.e. fibre, matrix resin, and $\mathrm{NaOH}$ as treatment solution, parameters of treatment, fabrication of composites and determining the flexural properties. The matrix selected for the study was epoxy resin and the ratio between resin and hardener was $4: 1$ by weight. The sugar palm fibre was collected from Banda Aceh, Indonesia, and a retting process was applied in order to separate the stalk from the core of fibre. In this process, bundles of sugar palm fibre were soaked in a water tank until the dirt vanished from the core section and the stalk was separated from the core. The sugar palm fibre stalks were occasionally stirred to facilitate the separation process. The water was changed several times in order 
to reduce the dirt resulting from the retting process. Before using the sugar palm fibre, it was dried for about two weeks at room temperature. Figure 1 shows the bundle of sugar palm fibres. The chemical treatment solution was sodium hydroxide $(\mathrm{NaOH})$ commercially supplied by Fisher Chemicals Co. This solution was prepared in liquid form in the bottle with a concentration of $1 \mathrm{M}$.

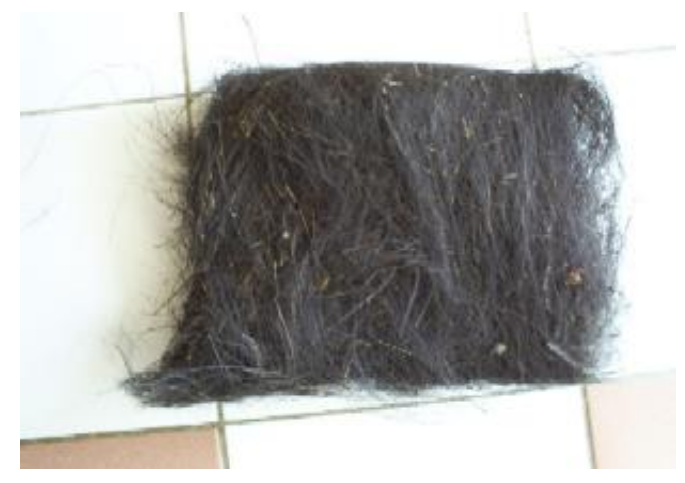

Figure 1: Bundle of sugar palm fibres

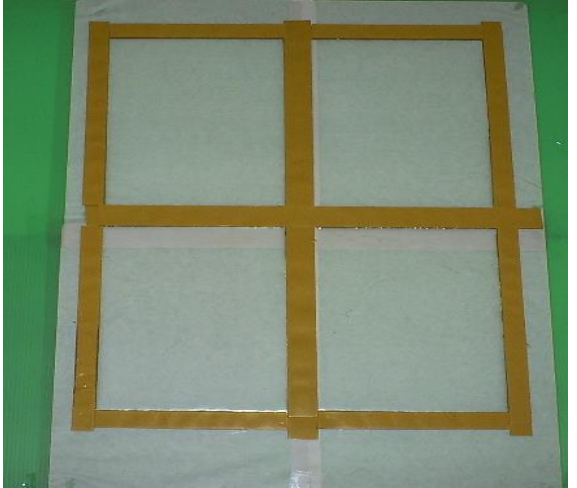

(a) before fibre loading

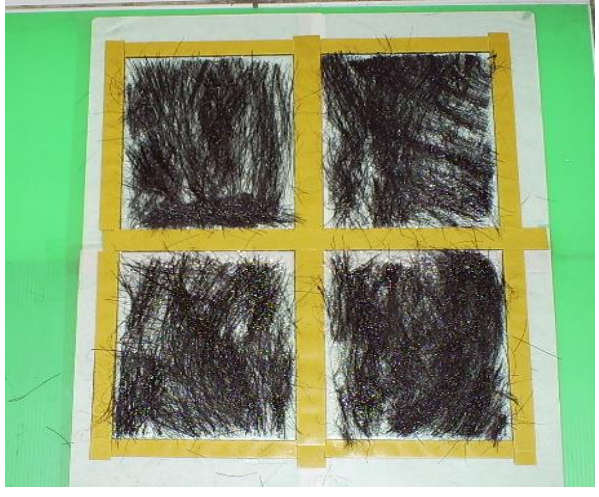

(b) after fibre loading

Figure 2: The process of making a specimen

The alkaline treatment was conducted with concentrations of $0.25 \mathrm{M}$ and $0.5 \mathrm{M}$ $\mathrm{NaOH}$, at three different soaking times, namely, 60 minutes, 4 hours and 8 hours. These variations were made to optimize the treatment parameter. The concentrations were ensured by the addition of water at certain percentages of the original $\mathrm{NaOH}(1 \mathrm{M})$. Sugar palm fibres were immersed in $\mathrm{NaOH}$ solution at various concentrations and soaking times, and after that they were rinsed with distilled water until the rinsed solution reached neutral ( $\mathrm{pH} 7)$. Then, the fibres were dried at room temperature for 4 days. The mould for preparing the specimens with hand lay-up technique was made of composite boards with the dimensions of $200 \mathrm{~mm}(\mathrm{~L}) \times 150 \mathrm{~mm}(\mathrm{~W})$ and a thickness of $3.2 \mathrm{~mm}$. The required equipment for making the mould for the hand lay up process were glass, transparent plastics for the bottom layer, and a spacer frame.

The mould was made from the glass and transparent plastic and the process of making the mould used 3 layers of double-sided tape to form a square shape. The treated and untreated fibres were cut based on the mould size. Then the fibre was placed 
over the transparent plastic in the bottom of the mould prepared earlier. Figure 2 shows the mould before and after fibre loading.

First, epoxy and hardener were mixed together based on the weight percentage to form a matrix, and then the matrix was poured over the fibre and compressed and distributed evenly until it achieved the thickness of between $3.0 \mathrm{~mm}$ and $3.2 \mathrm{~mm}$. After that, the remaining mixture of epoxy resin and hardener was poured over the unfinished composite plate and then pressed and pushed down with a finger to remove the bubbles. The optimum way to ensure good curing to produce a standard quality specimen was by mixing the epoxy and hardener for approximately 10 minutes. The curing time was around 20-24 hours applied at the room temperature condition of $25-30{ }^{\circ} \mathrm{C}$ until the composite plate dried evenly. For the sugar palm epoxy composites, flexural properties such as flexural strength and flexural modulus were determined. Each composite board was cut into test samples (three or four specimens for each type of fibre model were tested). The cutting process used a handsaw and other equipment (jigsaw). The dimension of the specimen used to carry out test was adapted from ASTM D790-99 (2000) for flexural testing. All these tests were carried out for untreated and treated sugar palm fibre reinforced epoxy composites.

Flexural tests were performed on a universal testing machine (Instron 5566) using the 3-point bending method according ASTM D790-99 (2000). The specimen dimensions were $127 \mathrm{~mm}(\mathrm{~L}) \times 12.7 \mathrm{~mm}(\mathrm{~W})$ and $3.2 \mathrm{~mm}$ thickness. The specimens were tested at a crosshead speed of $5 \mathrm{~mm} / \mathrm{min}$. The bending stress is calculated from the measured load, as follows:

$$
\sigma_{\max }=\frac{3 P L}{2 b a^{2}}
$$

where,

$\sigma_{\max }=$ flexural strength, $P=$ load at yield (max. load), $L=$ support span (mm), $b=$ width $(\mathrm{mm}), d=$ thickness $(\mathrm{mm})$.

Finally, an SEM micrograph PHILIPS was used to identify the fracture morphology of the composite samples and verify what happened in the interface between the fibre and matrix after stress loading.

\section{RESULTS AND DISCUSSION}

Table 1 shows the results for the flexural properties of sugar palm composite comprising the untreated specimens and the alkali treated specimens with different concentrations and soaking times. Both the flexural strength and flexural modulus values were extracted from each of the three specimen samples and represented by the mean value and standard deviation. For a clear understanding about these results, for a detailed discussion of the flexural strength and flexural modulus follows. 
Table 1: The flexural properties of a sugar palm fibre reinforced epoxy composite

\begin{tabular}{ccrrl}
\hline No. & Type & $\begin{array}{c}\text { Strength } \\
\text { MPa }\end{array}$ & $\begin{array}{c}\text { Modulus } \\
\text { MPa }\end{array}$ & \\
\hline 1 & no treatment & 77.73 & 2805.23 & mean \\
& & 9.39 & 927.54 & S.D. \\
2 & $0.25 \mathrm{M} / \mathrm{1} \mathrm{hr}$ & 96.69 & 3510.54 & mean \\
& & 22.14 & 566.25 & S.D. \\
3 & $0.25 \mathrm{M} / 4 \mathrm{hrs}$ & 64.42 & 2213.25 & mean \\
& & 6.47 & 381.66 & S.D. \\
4 & $0.25 \mathrm{M} / 8 \mathrm{hrs}$ & 72.63 & 2548.92 & mean \\
& & 16.27 & 242.52 & S.D. \\
5 & $0.5 \mathrm{M} / 1 \mathrm{hr}$. & 85.30 & 5028.92 & mean \\
& & 30.17 & 1146.42 & S.D. \\
6 & $0.5 \mathrm{M} / 4 \mathrm{hrs}$. & 58.17 & 6947.88 & mean \\
& & 8.97 & 1389.59 & S.D. \\
7 & $0.5 \mathrm{M} / 8 \mathrm{hrs}$. & 90.68 & 4672.49 & mean \\
& & 5.00 & 1227.32 & S.D. \\
\hline
\end{tabular}

S.D. is standard deviation

\section{Flexural Strength}

Figure 3 shows the flexural strength of sugar palm epoxy composites for untreated and alkali treated. From this figure, it is seen that a variation in the flexural strength appears upon a change in the type of treatment. From Figure 4, the flexural strength of the composites with the $0.25 \mathrm{M} \mathrm{NaOH}$ treatment shows a dominant value over that of the $0.5 \mathrm{M} \mathrm{NaOH}$ for 1 hour and 4 hours soaking time, but is inferior for 8 hours. However, the optimum value of the flexural strength $(96.71 \mathrm{MPa})$ is for the case of $1 \mathrm{hr}$ of soaking time at $0.25 \mathrm{M}$ alkali concentration, i.e. an increase of $24.41 \%$ from untreated composite. Bledzki and Gassan (1999) reported on the alkali treatment of natural fibre removal of lignin and hemicellulose. When hemicelluloses are removed, the interfibrillar region is likely to be less dense and less rigid and thereby makes the fibrils more capable of rearranging themselves along the direction of stress loading. When fibres are stretched, such rearrangements amongst the fibrils would result in better load sharing by them and hence result in higher stress development in the fibre. According to Cao et al. (2005) the fibres in the untreated fibres were packed together but got split after the treatments. This is called fibrillation, which breaks the untreated fibre bundle down into smaller ones by dissolution of the hemicellulose. The fibrillation increases the effective surface area available for contact with the matrix, and hence the interfacial was improved. 


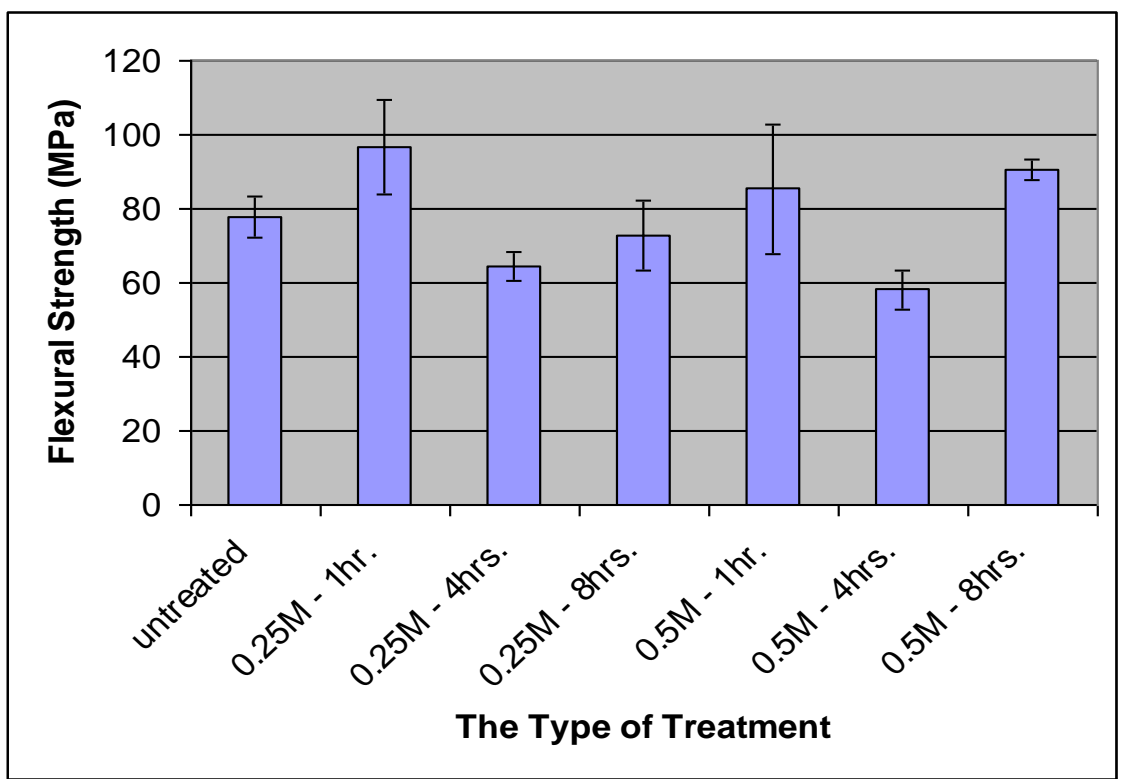

Figure 3. The flexural strength of sugar palm epoxy composites for untreated and alkaline treated.

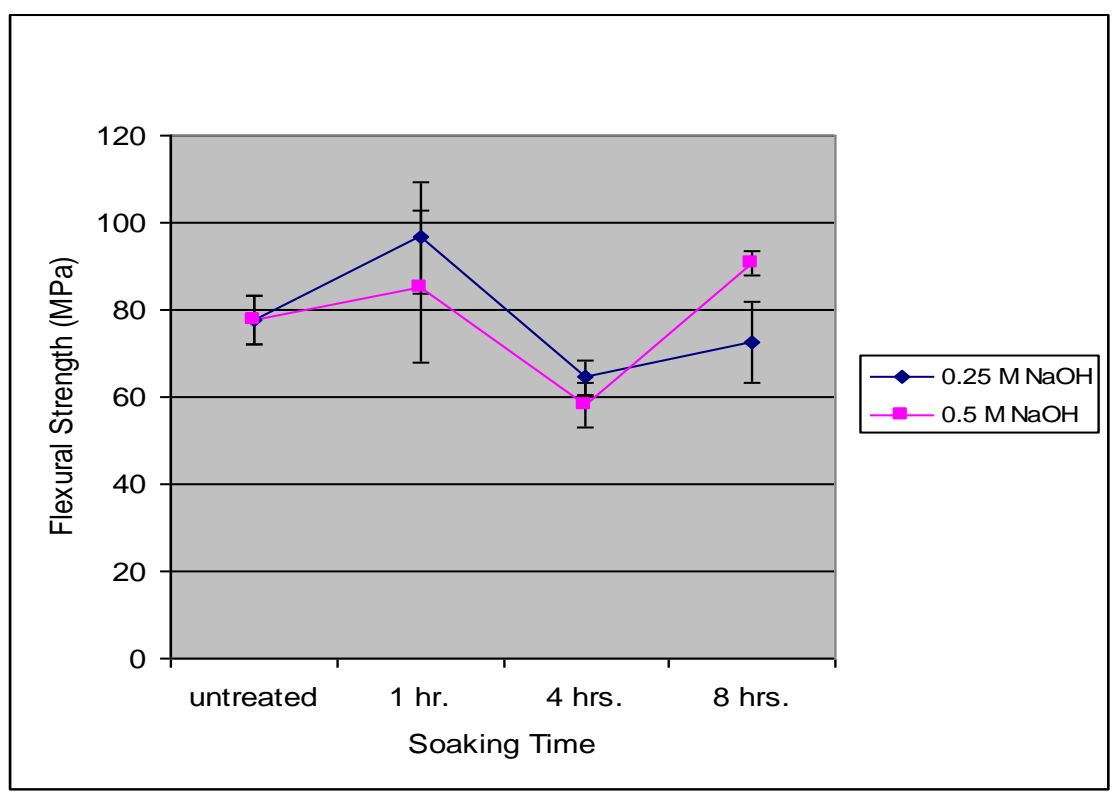

Figure 4. Average flexural strength of sugar palm fibre reinforced epoxy composite vs. soaking time 


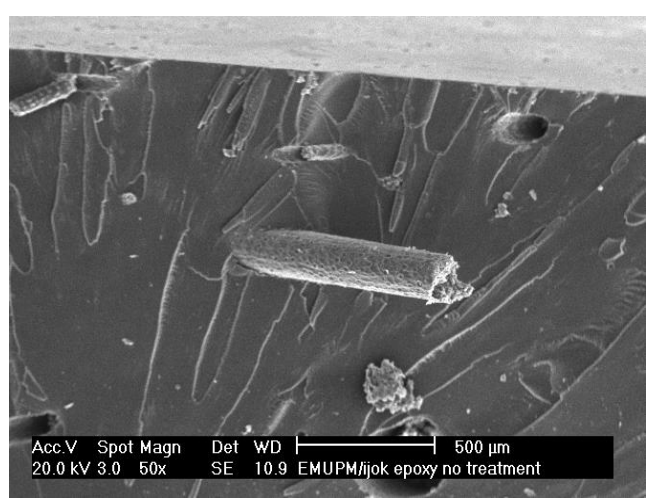

(a) untreated composites

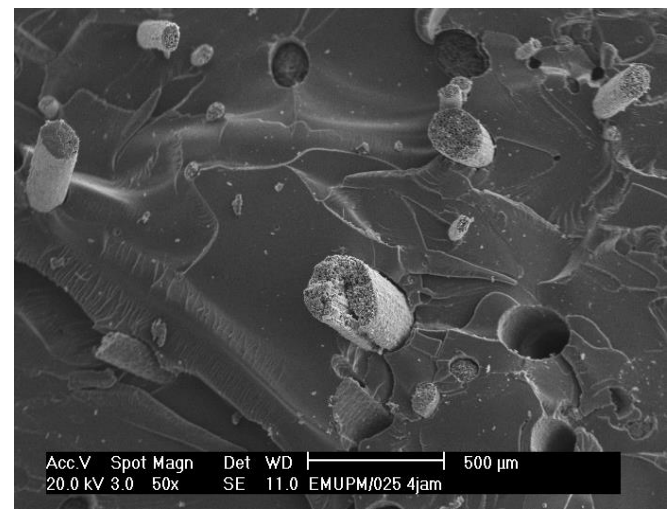

(c) $0.25 \mathrm{M}$ alkaline treated for 4 hours

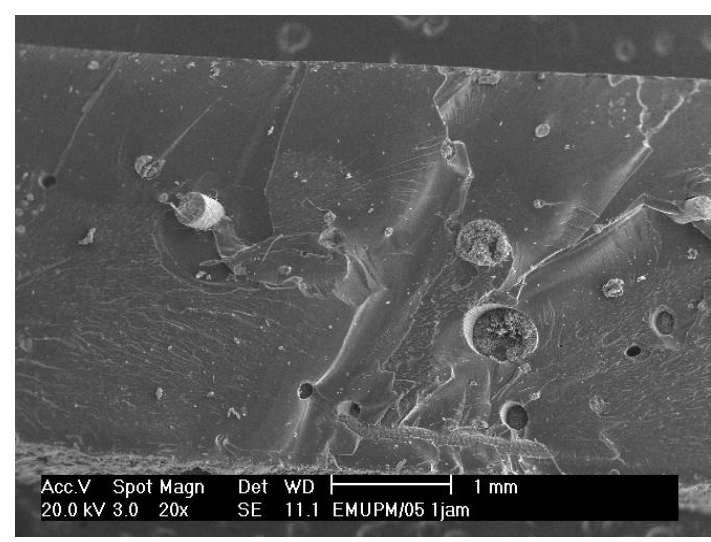

(e) $0.5 \mathrm{M}$ alkaline treated for 1 hour

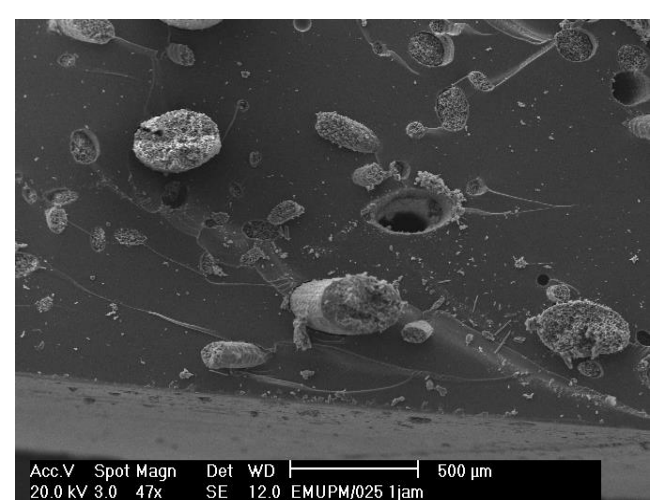

(b) $0.25 \mathrm{M}$ alkaline treated for 1 hour

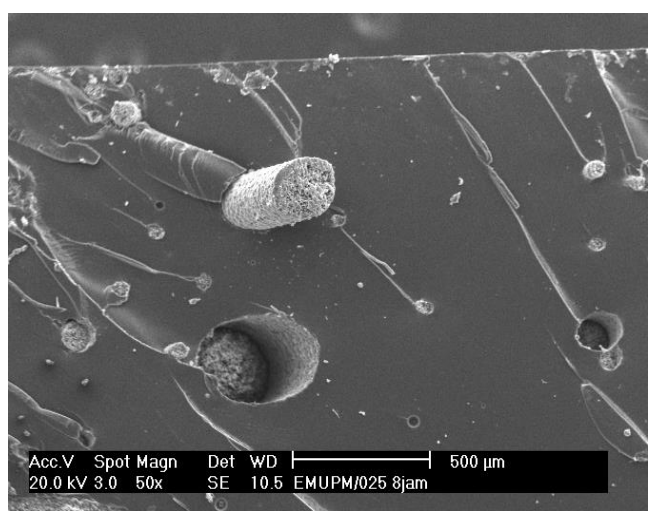

(d) $0.25 \mathrm{M}$ alkaline treated for 8 hours

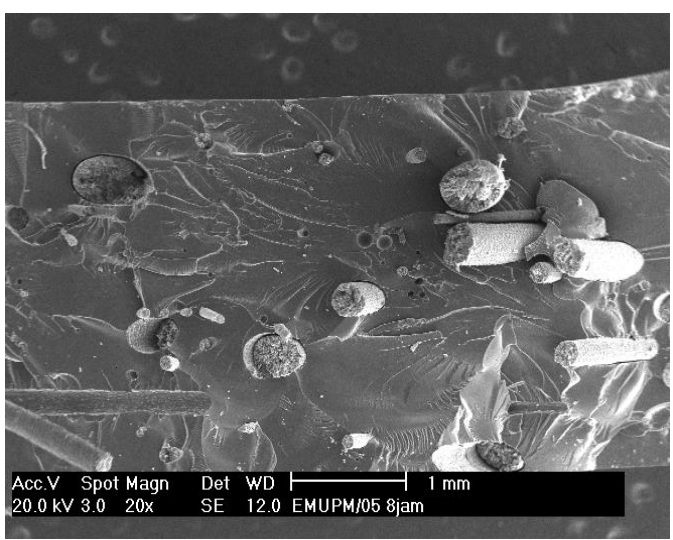

(f) $0.5 \mathrm{M}$ alkaline treated for 8 hours

Figure 5: The SEM visualization of fracture characteristics of sugar palm fibre reinforced epoxy composites. 


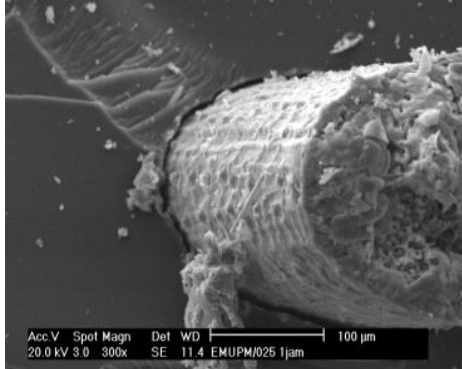

(a)

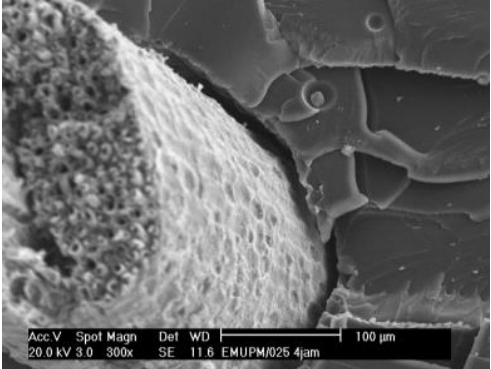

(b)

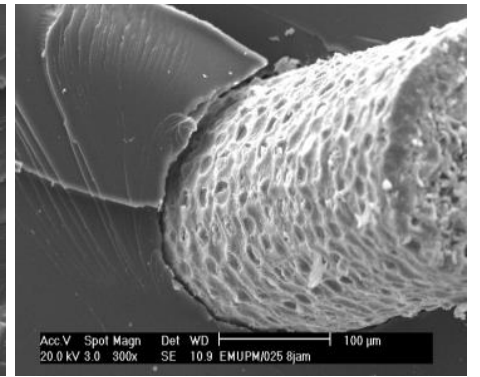

(c)

Figure 6: The surface of fibre for 1, 4 and 8 hours soaking time

Alkaline treatment also significantly changes the strength properties of individual natural fibre. Edeerozey et al. (2007) reported their study on the effect of a high concentration of alkaline solution on kenaf fibre. From the fibre bundle test, fibre treated with $6 \% \mathrm{NaOH}$ show the maximum value of strength, and when the $\mathrm{NaOH}$ concentration is increased to $9 \%$, the average of strength has shown a significant decrease. Hence, the combination between the strength characteristics of the fibre and characteristics of interfacial bonding between fibres and matrix contribute to yield the final flexural strength of the composites.

Figure 5 shows the morphology of the fracture surface of the sugar palm fibre reinforced epoxy composites for untreated and all types of alkaline treatment. The weak bonding between fibre and matrix is indicated by holes as a result of the pull-out of the fibre from matrix locking. And the good interfacial bonding between the fibre and matrix is indicated by the existence of the fibre on the matrix although the composites break after stress loading. Figure 5 verifies the value of flexural strength from the experiment. The sample with less flexural strength is indicated by the amount of holes which is much more than that of the other sample with higher flexural strength. The sample treated with $0.5 \mathrm{M}$ alkaline and 8 hours soaking time shows good interfacial bonding as indicated by the presence of fewer holes in the fracture surface. But, the final flexural strength is still low compared with the other alkali treatment that gives the maximum value. This is maybe due to the weakness of the individual fibre caused by the high concentration of alkaline treatment. The maximum strength was reached at a soaking time of 1 hour for $0.25 \mathrm{M} \mathrm{NaOH}$, and the strength decreased for 4 and 8 hours soaking time. Alkaline treatment affects the surface roughness and fibre strength. Figure 6 shows that there is not much difference on the surface of fibre for 1,4 and 8 hours soaking time. Hence, the decrease of strength may be caused by a decrease of the fibre strength itself as the effect of the soaking time. Figures 7 and 8 also show the comparison between the surface of the $0.5 \mathrm{M} / 8 \mathrm{hrs}$. treated sugar palm fibre on epoxy matrices and the surface of the $0.25 \mathrm{M} / 8 \mathrm{hrs}$. treated sugar palm fibre on epoxy matrices. The surface in Figure 7 is rougher than the surface in Figure 8, indicating that a higher concentration alkali solution contributes to change the smoothness of that fibre surface. 


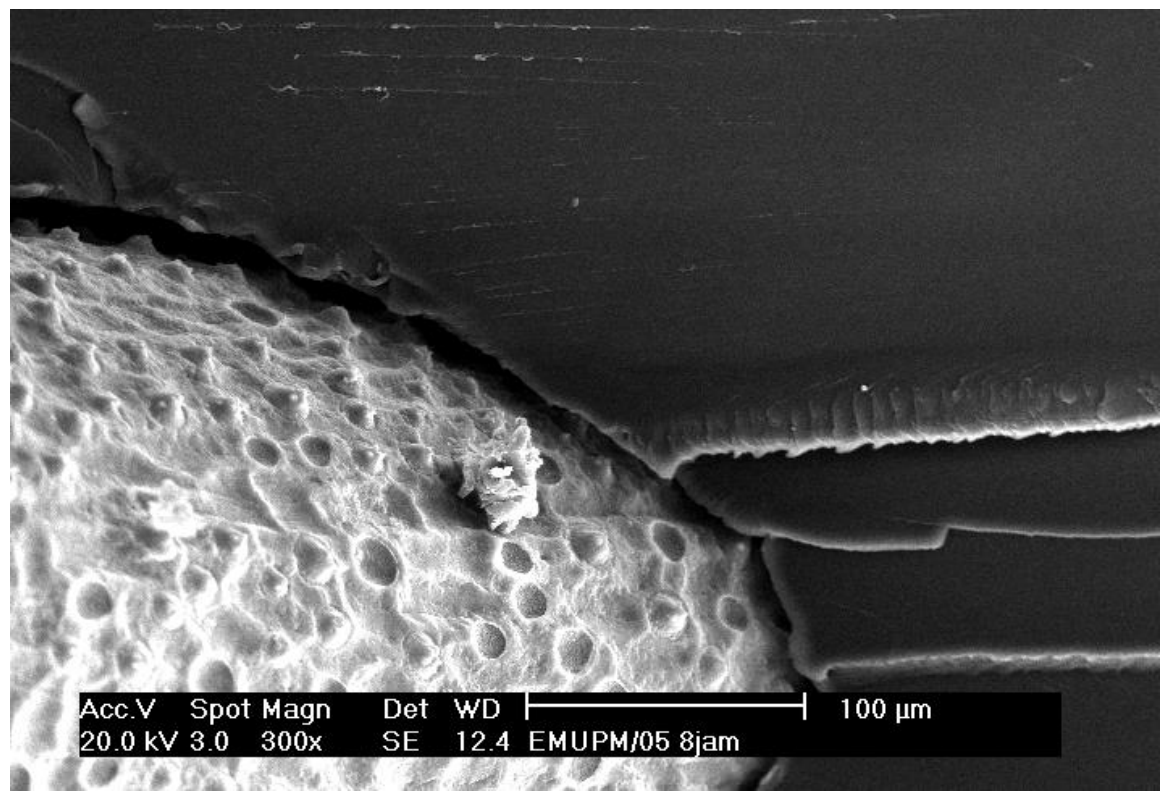

Figure 7: The surface of the $0.5 \mathrm{M} / 8 \mathrm{hrs}$. treated sugar palm fibre on epoxy matrices

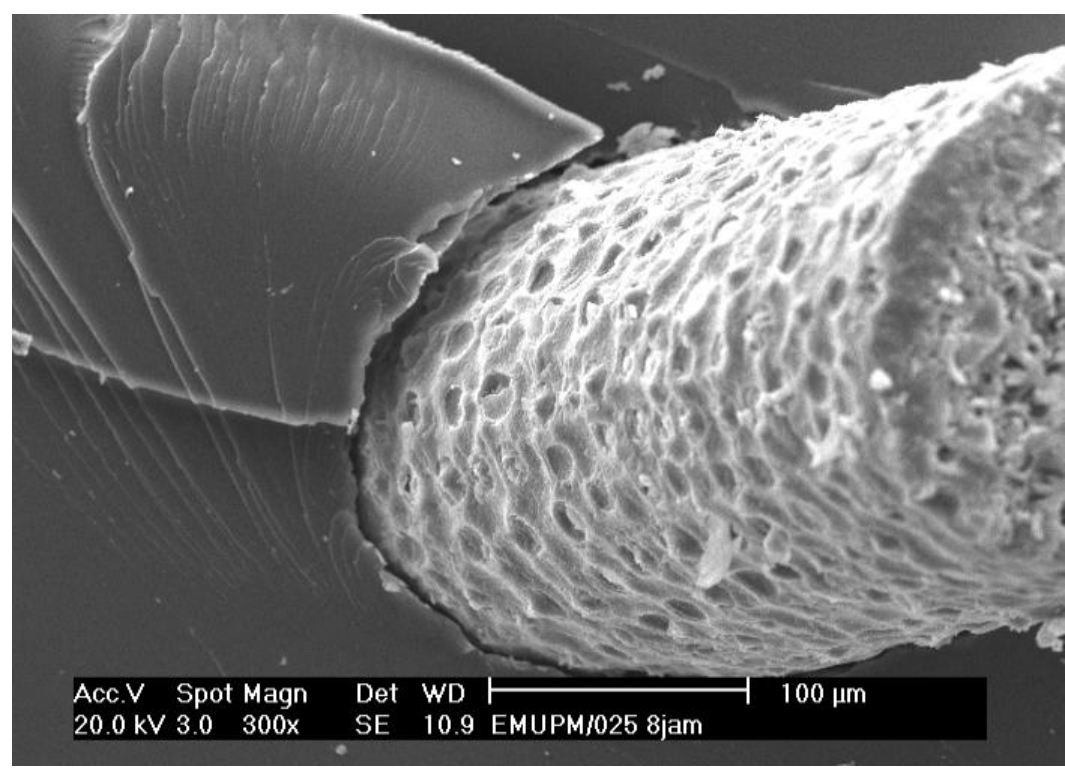

Figure 8: The surface of the $0.25 \mathrm{M} / 8 \mathrm{hrs}$. treated sugar palm fibre on epoxy matrices

\section{Flexural Modulus}

Figure 9 shows the flexural modulus of sugar palm epoxy composites for untreated and the alkali treated. It is seen that the improvement of the flexural modulus emerges when the concentration of treatment solution increases to $0.5 \mathrm{M}$. Although the modulus decrease at soaking time 8 hours, but still high compare to the modulus of composites with $0.25 \mathrm{M} \mathrm{NaOH}$ treatment. 


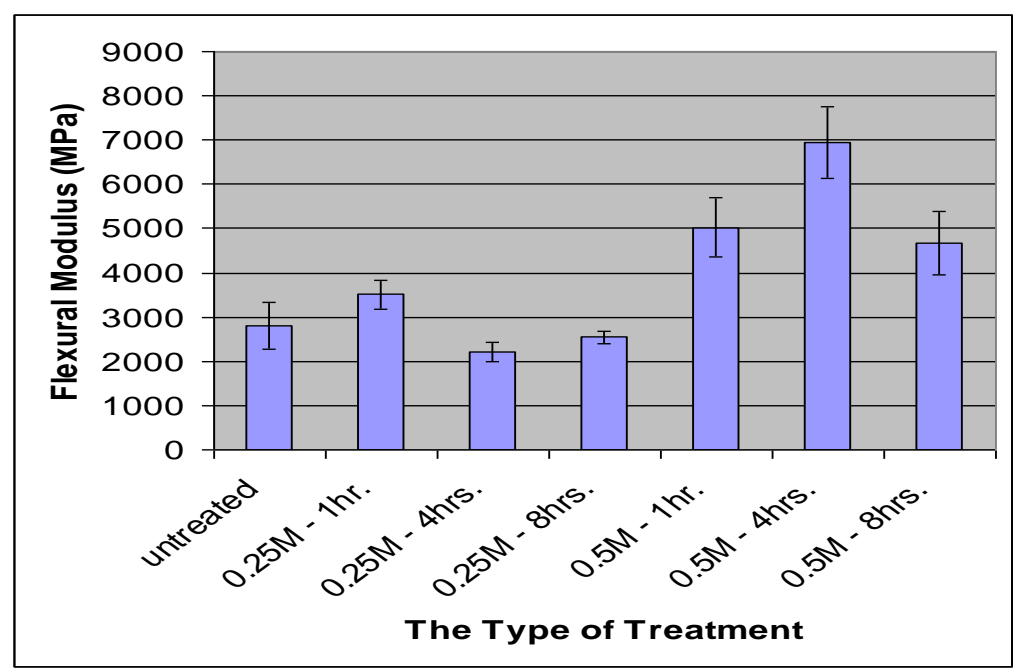

Figure 9: The flexural modulus of sugar palm epoxy composites for untreated and the alkali treated.

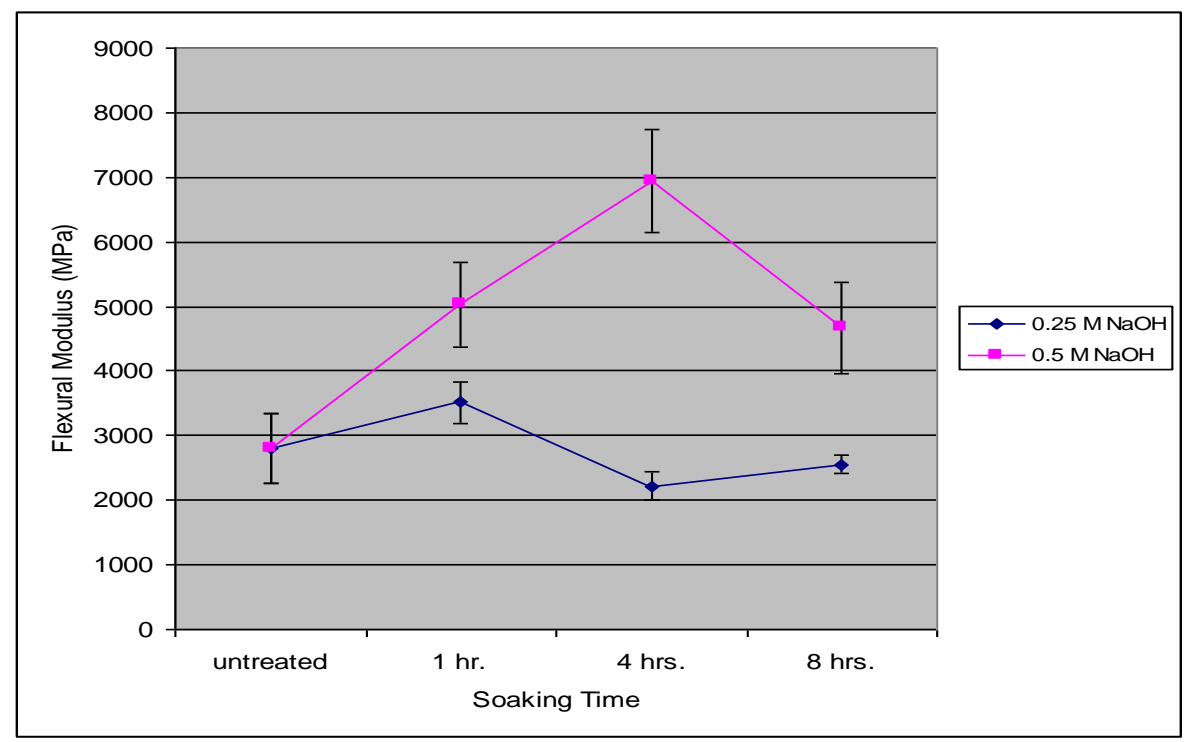

Figure 10: Average flexural modulus of sugar palm fibre reinforced epoxy composite vs. soaking time

The flexural modulus is the stiffness parameter and Figure 10 shows the flexural modulus versus the soaking time, it is seen the comparison of flexural modulus of 0.25 $\mathrm{M}$ alkaline treated composites with the $0.5 \mathrm{M}$ alkaline treated. Alkaline treatment with $0.5 \mathrm{M} \mathrm{NaOH}$ increases the flexural modulus of sugar palm reinforced epoxy composites. And the treatment with $0.25 \mathrm{M} \mathrm{NaOH}$ produces the same modulus as that of the untreated composites. Rong et al. (2001) reported that the alkali treatment for sisal fibres provides improved crystallinity of cellulose and removes the hemi-cellulose and lignin content. This suggests that sisal fibre becomes relatively ductile after the removal of some hemi-cellulose and lignin. This can result in higher fibre stiffness due to the increased crystallinity of hard cellulose. For the case of sugar palm fibre, a similar reason for the improvement in the flexural modulus is viewed. 


\section{CONCLUSIONS}

It can be concluded that the maximum flexural strength $(96.71 \mathrm{MPa})$ of the composite is for the alkali treatment of $0.25 \mathrm{M}$ alkali solution and $1 \mathrm{hr}$ soaking time. Under that condition, the increase of flexural strength from the untreated sample is about $24.41 \%$. But, the maximum flexural modulus took place as a result of the $0.5 \mathrm{M} \mathrm{NaOH}$ solution with 4 hours soaking time, i.e. $6948 \mathrm{MPa}$, an improvement of 148\% from the untreated fibre composite. The high concentration of the alkali treatment provides for increasing of the flexural modulus significantly. It may be caused by the alkaline effect on fibres that increases their crystallinity.

\section{ACKNOWLEDGEMENTS}

The authors are indebted to staff at the Faculty of Engineering and Faculty of Forestry, Universiti Putra Malaysia and Malaysian Nuclear Agency (MNA) for their support.

\section{REFERENCES}

ASTM D790-99. (2000) Standard test method for flexural properties of unreinforced and reinforced plastics and electrical insulating materials. USA: American Society for Testing Materials.

Bledzki, A.K. and Gassan, J. (1999) Composites Reinforced With Cellulose Based Fibres. Progress in Polymer Science, 24: 221-274.

Cao, Y., Shibata, S. and Fukumoto, I. (2005) Press Forming Short Natural FiberReinforced Biodegradable Resin: Effect of Fiber Volume and Length on Flexural Properties. Polymer Testing, 24: 1005-1011.

Edeerozey, A.M.M., Akil, H.M., Azhar, A.B. and Ariffin, M.I.Z. (2007) Chemical Modification of Kenaf Fibres. Material Letters, 10: 2023-2025.

Herrera-Franco, P.J. and Valadez-Gonzalez, A. (2004) Mechanical Properties of Continuous Natural Fibre-Reinforced Polymer Composites. Composites Part A: Applied Science and Manufacturing, 35: 339-345.

Rong, M.Z., Zhang, M.Q., Liu, Y., Yang, G.C. and Zeng, H.M. (2001) The Effect of Fiber Treatment on the Mechanical Properties of Unidirectional Sisal Reinforced Epoxy Composites. Composites Science and Technology, 61: 1437-1447.

Rowell, R.M. (1998) Property Enhanced Natural Fibre Composite Material Based on Chemical Modification. in: Science and Technology of Polymers and Advanced Materials, Prasad, P.N. (Ed.). New York: Plenum Press, pp. 717-732.

Saheb, N.D. and Jog, J.P. (1999) Natural Fibre Polymer Composites: A Review. Advanced Polymer Technology, 18: 351-363.

Siregar, J.P. 2005. Tensile and Flexural Strength of Arenga pinnata Filament (Ijuk Filament) Reinforced Epoxy Composites. Master of Science thesis. Universiti Putra Malaysia.

Suriani, M.J., Hamdan, M.M., Sastra, H.Y. and Sapuan, S.M. (2007) Study of nterfacial Adhesion of Tensile Specimens of Arenga Pinnata Fiber Reinforced Composites, Multidiscipline Modeling in Material and Structure, 3(2): 213-224.

Suwartapraja, O.S. (2003) Arenga pinnata: A Case Study of Indigenous Knowledge on the Utilization of a Wild Food Plant in West Java.

www.geocities.com/inrik/opan.htm (accessed on 1301 2008) 
Wambua, P., Ivens, J. and Verpoest, I. (2003) Natural Fibres: Can They Replace Glass in the Fibre-Reinforced Plastics? Composites Science and Technology, 63: $1259-1264$.

Wool, R.P. (2005) Bio-based Composites From Soybean Oil and Chicken Feathers. In: Bio-Based Polymers and Composites. Wool, R.P. and Sun, X.S. (Eds.). Burlington: Elsevier Academic Press. 